\title{
Young New Zealanders' Beliefs About Youth Suicide and How It
}

\section{Can Be Prevented}

\author{
Mikayla S. Holman \& Matt N. Williams \\ Massey University, New Zealand
}

New Zealand has the highest suicide rate amongst youth (ages 15-24) in the OECD. We aimed to conduct a conceptual replication of two previous studies, examining the views that youth in New Zealand hold about the causes of youth suicide, possible solutions, and help-seeking. One hundred university students aged 18 to 24 completed a mixed-methods online survey; $89 \%$ were female. One of four hypotheses was supported: Students who were personally aware of another student's suicidality were more willing to seek help for others from the university counselling service. Qualitative findings indicated that bullying and stigma were the most commonly perceived causes of youth suicide, and improvement of mental health services was the most frequently recommended solution. The views of youth should be included in the future development of mental health services and policies aimed at reducing suicide rates for this population.

Keywords: help-seeking, mental health services, suicide, university, youth

\section{Introduction}

Suicide is a leading cause of death in many countries, with an estimated 800,000 suicide deaths worldwide each year (World Health Organization, 2018). In 2012, New Zealand had the highest suicide rate out of all OECD countries for youth aged 15 to 24 (Ministry of Social Development, 2016). Currently, a young person in New Zealand dies by suicide every sixty-four hours (Coronial Services of New Zealand, 2018). In the year to June 2018, those aged 15 to 19 died by suicide at a rate of 16.88 per 100,000 , while those aged 20 to 24 had a suicide rate of 21.21 per 100,000 (Coronial Services of New Zealand, 2018).

Youth aged 15 to 24 consistently report the highest rates of psychological distress compared to other age groups in New Zealand, with $11.8 \%$ of youth scoring 12 or higher on the Kessler Psychological Distress Scale-10 in a Ministry of Health (2017) survey. However, those towards the upper end of the youth age range, the 20 to 24 year olds, are the ones who more often die by suicide (Beautrais, 2003). University students aged under 24 are a particularly vulnerable population, reporting higher levels of psychological distress than non-university populations of the same age (Stallman, 2010). Counselling services offered by universities New Zealand-wide are experiencing surges in the number of youths trying to access these services, with an overall increase of nearly 25\% between 2015 and 2017 (New Zealand Union of Students' Associations, 2018). These circumstances suggest that suicide prevention services or programmes specifically designed for this population need to be developed.

Why Research Young People's Beliefs About Youth Suicide?

The Mental Health Commission (2012) reports that service users and their families frequently express the need for inclusion in the development of policies and services. This inclusion promotes self-determination, empowering individuals to share the decision-making process with professionals, and increasing treatment adherence (Corrigan et al., 2012). Self-determination is a crucial factor in whether service use will result in recovery (Mental Health Commission, 2012), and has implications for suicide prevention specifically. Understanding the beliefs young people hold about suicide could impact mental health services targeted towards this population, and in combination with the knowledge of mental health professionals, the content and delivery of such services could be adapted to increase their relevance and effectiveness for youth. This has the potential to save the lives of more young New Zealanders who access these services during times of distress.

The New Zealand Government (2018) Inquiry into Mental Health and Addiction report states that one of the purposes of their inquiry was "to hear the voices of the community, people with lived experience of mental health and addiction problems, people affected by suicide, and people involved in preventing and responding to mental health and addiction problems, on New Zealand's current approach to mental health and addiction and what needs to change" (p. 6). The purpose of the present study was in effect the same- to hear the voices of young people, many of whom have been impacted by suicide. It was not assumed that the views youth hold about the causes of suicide would be accurate. Irrespective of their accuracy, researching their views may have important implications. For example, if there was a disparity between what research suggests is effective in preventing youth suicide and what youth believe to be effective, then it may be the case that more public health promotion is needed to dispel myths and increase accurate knowledge of suicide prevention methods.

At present there are a small number of studies in New Zealand that have attempted to research beliefs about youth suicide among university students. Two of these studies that are of particular relevance to this study are by Heled and Read (2005) and Curtis (2010).

Heled and Read (2005) researched youth perceptions 
of suicide and its solutions. Undergraduate students at the University of Auckland were asked for possible reasons for why the youth suicide rate was high and suggestions for how the rate could be reduced, with students providing qualitative responses to these questions. Participants believed the greatest cause of youth suicide to be pressure from adults or peers, followed by financial worries and poor job prospects. A tenth of the participants perceived that insufficient, poorly advertised, and inaccessible support services contributed to the high rate of youth suicide. Participants suggested that to reduce the suicide rate, public awareness was important. Other suggestions included creating support groups and increasing the availability of and access to counselling.

Curtis (2010) examined perceptions of youth at Wellington's Victoria University towards suicide and help-seeking behaviour. Students largely agreed that they would contact a university mental health service for themselves (49.8\% strongly agree or agree) and small but significant gender differences were found, with females more likely to seek help for themselves than males were. Students who had their own experience of suicidality were more confident that they could identify an at-risk student, and less likely to believe suicide could be prevented. Groups of students were interviewed in a second phase of Curtis' (2010) study, during which many students said that when concerned about another student they would prefer to be self-reliant or seek help from family and friends, rather than turning to professional services such as those offered by the university.

\section{Research Aims}

In light of the findings reported by the two studies above, this study aimed to investigate perceptions of the high youth suicide rate in New Zealand among young university students at Massey University, and to examine help-seeking behaviour of those students.

This study is a conceptual replication of parts of the two studies described earlier, neither of which were preregistered. The strategy of preregistration has grown in popularity in psychology in recent years in response to well-known problems with the reproducibility of psychological studies (see Nosek, Ebersole, DeHaven, \& Mellor, 2018; Open Science Collaboration, 2015; Pashler \& Wagenmakers, 2012). Preregistering data collection and analysis plans prior to collecting data limits the capacity of the researcher to exploit "researcher degrees of freedom" (Simmons, Nelson, \& Simonsohn, 2011, p. 1359) in order to produce statistically significant findings - a practice also known as "p-hacking" (Head, Holman, Lanfear, Kahn, \& Jennions, 2015). As such, this study was preregistered on the Open Science Framework (see Method for details), with hypotheses, method, and analyses decided upon prior to data collection. The focus of this study was on the perceived causes of youth suicide, strategies that youth believed could decrease this rate, and their current helpseeking behaviour towards Massey University's counselling service.

Both Heled and Read's (2005) and
Curtis' (2010) studies were original research and were largely exploratory. Because of this, this study had only a few hypotheses, all of which were based on a small selection of key statistically significant differences found by Curtis. The hypotheses were: 1) female students will be more likely than male students to say they would seek help if experiencing personal, health or work-related issues; 2) students who are personally aware of another student's suicidality will be more willing to seek help for others from the university counselling service; 3 ) students who have been suicidal themselves will feel more confident that they can identify students at risk of suicide; and 4) students who have been suicidal themselves will be less likely to believe that suicide can be prevented.

\section{METHODS \\ Participants and Procedure}

A sample of students from Massey University were recruited for this study. A university population was used in both Heled and Read's (2005) and Curtis' (2010) studies, and it was a convenient, accessible population for this study as well. A questionnaire was used for data collection, which was distributed to students via their undergraduate course websites and social media. As specified in the study's preregistration, accessible at https://osf.io/t3ynv, the questionnaire remained online for six weeks, during which time 140 students responded. Of these responses, there were 100 that met the inclusion requirements of the preregistration (e.g., answered at least half of the questions that were going to be analysed). Of the 40 participants excluded by this rule, 9 stopped filling out the survey after the consent item, and 31 after the first page of questions. The preregistration specified that if there were remaining missing values on quantitative variables after applying this exclusion rule, single imputation would be executed. Of the 100 responses included in the analyses, none required imputation for missing values. The overall sample size for the study was only moderate, but delivered adequate power for the correlational analyses that were used to test the majority of hypotheses: An $N$ of 100 provides $86 \%$ power to detect a medium-size correlation of $\rho=.3$ in a 2 -tailed test.

Participant demographics. The age of participants ranged from 18 to 24 , with a mean age of 21.38 ( $S D=$ 2.00). Females were over-represented in this study,

\begin{tabular}{lc}
\hline Table 1. Participant Demographics & \\
\hline Variable & \\
& \\
\hline Gender & 89 \\
Female & 10 \\
Male & 1 \\
Gender diverse & 76 \\
Ethnicity & 8 \\
Nerw Zealand European/ Pākehā & 4 \\
Māori & 4 \\
Pacific Island & 8 \\
Asian & 43 \\
Other & 23 \\
Area of study & 12 \\
Psychology & 5 \\
Social sciences and humanities (excluding psychology) & 4 \\
Business & 13 \\
Health sciences (excluding psychology) & \\
Physical or mathematical sciences & \\
Other &
\end{tabular}


making up $89 \%$ of the sample (see Table 1).

\section{Measures}

A questionnaire containing 27 items was used for the study. This can be viewed at https://osf.io/n5zc8/. The first five items were related to demographic information, asking participants about their gender, age, ethnicity, what region they live in, and their area of study at Massey University.

The following four items were replicated from Heled and Read's (2005) study. The first two of these items asked if participants knew a young person who had attempted suicide, or who had died by suicide. The next two items, also replicated from Heled and Read, asked participants what they perceived the causes of New Zealand's high youth suicide rate to be, and what they thought could be done to reduce the rate (with qualitative responses)

Fourteen items were based on items from Curtis' (2010) study, with small changes made to the wording of some items. Participants were asked to rate their level of agreement with statements about their help-seeking behaviour, such as "I would personally seek help from Massey University's Health \& Counselling Centre if I was experiencing personal, health or work-related issues". These items were rated on a Likert scale from 1 (strongly agree) to 5 (strongly disagree). To replicate the measurement used in the original study by Curtis (2010), participants' history of suicidality was measured by item 14 (I have personally sought help from Massey University's Health and Counselling Centre as a result of experiencing suicidal thoughts or feelings, or because I have engaged in suicidal behaviour).

A further three items were created specifically for this study. The first of these items asked participants what they would do to help a distressed or suicidal friend (with qualitative responses). Another item asked whether participants knew about the services offered by Massey University's Health and Counselling Centre. The last item asked participants to choose what their preferred method of booking an appointment at the Health and Counselling Centre would be: walk-in to make an appointment, phone call, email, Massey University website, or Massey University app.

\section{Data sharing policy}

A de-identified copy of the quantitative data has been transferred to an Open Science Framework project, along with analysis code that was used in $\mathrm{R}$ ( $\mathrm{R}$ Core Team, 2018). This can be accessed at https://osf.io/syxwr/. Qualitative responses will not be made openly accessible. It is impossible to guarantee that individual participants would be unidentifiable based on the details in these responses.

\section{Ethics approval}

Approval for this study was given by the Massey University Human Ethics Committee. Relevant suicide prevention help lines were provided to all participants both prior to and following completion of the questionnaire.

\section{Quantitative results}

\section{RESULTS}

\section{Descriptive statistics.}

Most participants in this sample personally knew a young person that had attempted suicide ( $82 \%)$, while just over half of all participants personally knew a young person that had died by suicide $(55 \%)$.

The distribution of responses to each Likert item is shown in Figure 1. The Likert scale ranged from 1 (strongly agree) to 5 (strongly disagree), the same scale used by Curtis (2010) for these items. Of the 100 participants in this sample, 29 had personally provided support to students at Massey University that were engaging in suicidal behaviour $(M=3.52, S D=1.45)$, and 30 had encouraged fellow students to seek support for suicidal behaviour $(M=3.37, S D=1.57)$.

For further information about the quantitative results, please see the Supplementary Materials at https://osf.io/khbvg/.

\section{Confirmatory analyses.}

A Welch's t-test was conducted to test hypothesis 1, that female students would show higher levels of agreement with the statement "I would personally seek help from Massey University's Health and Counselling Centre if I was experiencing personal, health or workrelated issues". Female participants indicated slightly more agreement with this statement $(M=2.70)$ than males did $(M=2.48)$. However, this difference was not statistically significant, $t(11.19)=0.52, p=.614, d=0.17$. The robustness of this result was checked with a MannWhitney $\mathrm{U}$ test (as per preregistration, section $\mathrm{C}$ ) which also showed a non-significant result, $W=493, p=.570$.

Pearson's correlation tests were conducted to test hypotheses 2, 3, and 4, followed by Spearman's rank correlation tests to check robustness (as per preregistration, section $\mathrm{C}$ ). These analyses found some support for hypothesis 2 . Being aware of another student's suicidality was positively correlated with being more likely to seek help for peers, Pearson's $r=.255, p=.010$; Spearman's $r \mathrm{~s}=.286, p=.004$. The third hypothesis was that students who had themselves been suicidal would be more confident that they could identify a student at risk of suicide. The analyses did not support this hypothesis, with the Pearson and Spearman's correlation tests both suggesting very small relationships that were not statistically significant, $r=-.015, p=.884 ; r \mathrm{~s}=.029, p=$ .771 . Hypothesis 4 was also not supported by the results of the correlation tests. Students who had themselves been suicidal were more likely to believe suicide was preventable, not less likely (as was hypothesised), with the analyses finding a weak positive correlation between the two variables, $r=.198, p=.048 ; r \mathrm{~s}=.210, p=.036$.

\section{Qualitative results}

The responses to each of the three qualitative questions were coded one question at a time, using a qualitative content analysis method as described by Forman and Damschroder (2007). This involved reading all responses to the question, followed by highlighting key words or phrases. These excerpts were typed into an Excel document, then all were read again before being coded inductively, with codes broadly describing the content of the excerpt. For example, "lack of conversation around the 


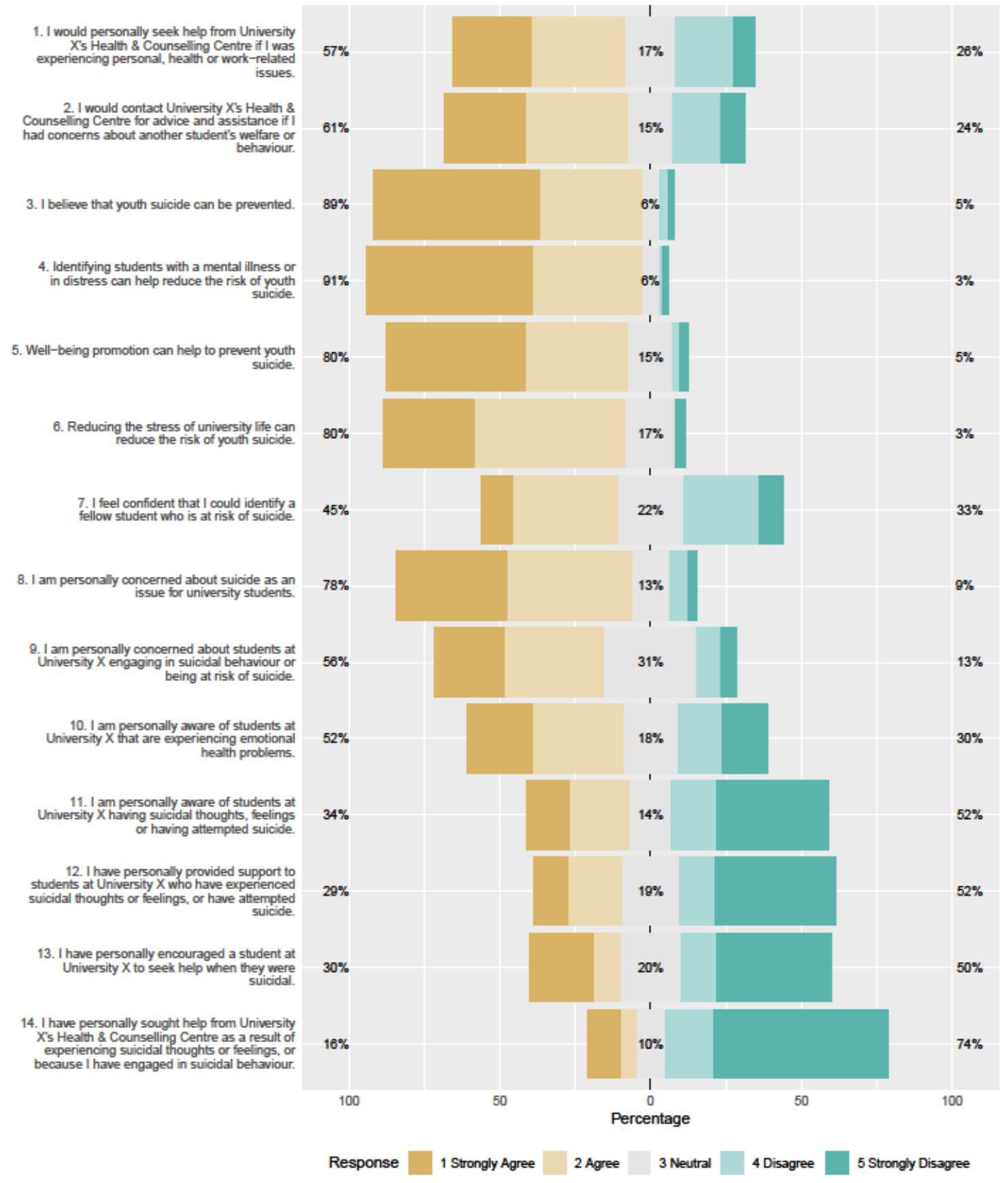

Figure 1. Bar plot of Likert items showing the percentage of each response category.

topic" was highlighted as a key phrase in one participant's response to the question "What do you think are causes of New Zealand's high youth suicide rate?" This was later grouped with similar excerpts from other participants like "lack of discussion amongst families, friends and society" and "I don't believe it is talked about enough" to create the broad code "not talking about it". The original responses were then read again to count the number of participants who mentioned this code, crossing off each associated excerpt to ensure all were counted. This process of coding responses occurred for each of the three qualitative questions. The total for each code is reported as the percentage of the sample that mentioned it. As each participant's response could be assigned to multiple codes, the codes were not mutually exclusive.
Participants' responses to the question "What do you think are causes of New Zealand's high youth suicide rate?" largely focused on factors that led to young people feeling suicidal. Bullying was the most commonly stated cause, being mentioned by $32 \%$ of participants. Stigma about mental illness and asking for help, as well as Kiwi expectations of stoicism (for example, the "she'll be right" mentality and the expectation to "harden up") were also thought to be largely at fault, mentioned by around a quarter of participants, at $23 \%$ and $25 \%$ respectively. A number of participants perceived mental health services to be a cause of the high youth suicide rate, with $14 \%$ claiming that these services were difficult to access, with long wait times and eligibility criteria that were too strict, while $9 \%$ perceived that the services were inadequate. 
Participants' responses to the question "What do you think could be done to reduce New Zealand's high youth suicide rate" saw many propose ways to improve mental health services for this age group. $37 \%$ of the sample said that providing a different type of service would help to reduce the rate, while $20 \%$ thought that increasing accessibility would result in an improvement. The need for education about mental health, suicide, and symptom recognition was also frequently mentioned.

In response to the question "If one of your friends was experiencing distress, suicidal thoughts, or suicidal behaviour, how would you go about helping them?" the majority of participants mentioned that they would seek professional help, while just under half would offer help, support, advice or guidance. Talking and listening were also frequently perceived to be ways to help a suicidal friend.

For further information about the qualitative results, please see the Supplementary Materials at https://osf.io/khbvg/.

\section{DISCUSSION}

Of the four hypotheses, only one was found to be supported (hypothesis 2). Similar to the findings of Curtis (2010), students who were aware of a peer's suicidality were significantly more likely to seek help for others.

There were multiple differences between the present study's results and the findings of Curtis (2010), with the remaining three hypotheses not supported. Curtis found a significant gender difference in how likely students were to seek help for themselves (hypothesis 1), while the present study did not find this result. This could be due to differences in the demographics of this sample compared to Curtis'. This study had only 10 male participants (10\%), limiting the statistical power of this analysis, while males made up 35.2\% of Curtis' sample.

The third hypothesis was that students who had been suicidal themselves would be more confident in identifying a student at risk of suicide (as reported by Curtis, 2010). This hypothesis was not supported. That said, the participants we identified as having been suicidal themselves were limited to those who gave an affirmative response to the item "I have personally sought help from Massey University's Health \& Counselling Centre as a result of experiencing suicidal thoughts or feelings, or because I have engaged in suicidal behaviour". This approach replicated that in Curtis (2010), but would not necessarily identify all students with a history of suicidal thoughts or behaviour. In future research, it may be more useful to use a general measure of history of suicidality when investigating this relationship.

The fourth hypothesis, that students who had themselves been suicidal would be less likely to believe that suicide could be prevented, was also not supported. Instead the opposite result to Curtis (2010) was found, with these students being significantly more likely to believe suicide could be prevented.

Nearly a third of the students in this sample (30\%) said they would encourage a student to get support for suicidal behaviour. This proportion was nearly double the proportion of Victoria University students who reported they would do so in Curtis (2010). This difference may be the result of the two studies having different samples from different universities, and taking place in different time periods, and thus there could be any number of factors that might explain these differences. The current study does not provide the basis for determining which factors are responsible for these differences, but such factors might include the much greater proportion of psychology students in the present study, public campaigns focused on mental health, and general societal changes in attitudes over time, among others.

The results of this study show that students at Massey University know of the services offered by the university's Health and Counselling Centre and many would be willing to utilise these services when in need themselves. Despite this willingness to seek help from the university's service, students held quite negative perceptions toward mental health services in general, mentioning barriers such as he services being inadequate or difficult to access, and having long wait lists or strict entry criteria, with such views repeated in other literature (e.g., Heled \& Read, 2005).

In order to rectify some of these barriers to seeking help from mental health services, students made suggestions such as providing access to free counselling across the country and making the process of seeking help clearer, as well as increasing awareness of available services. Despite the largely negative views towards mental health services, more than half of the present sample mentioned that they would seek professional help in order to assist a friend who was feeling suicidal. In contrast, Curtis' (2010) sample thought that seeking professional help was a last resort, with many preferring to seek the support of family and friends primarily.

There were a number of important qualitative results regarding what students believed to be the cause of youth suicide. The most commonly perceived cause of suicide for young New Zealanders was bullying, with nearly a third of the sample mentioning this. In comparison, Heled and Read (2005) had just $4.2 \%$ of their participants mention bullying as a cause of youth suicide. The high percentage reported in the present study is a result echoed by recent New Zealand research by Stubbing and Gibson (2018).

In the present study, suggestions from participants to reduce New Zealand's youth suicide rate included tackling stigma and raising awareness about mental illness and suicide, although how to do this was not specified. Such actions require change at a societal level to challenge the negative perceptions held about people who feel suicidal. Stigma surrounding suicide involves the perception that someone who attempts or completes suicide is selfish, cowardly, or attention-seeking, similar to stigma towards mental illness (Sheehan, Nieweglowski, \& Corrigan, 2017). Government-funded campaigns such as the ongoing 'Like Minds, Like Mine' campaign, have tried to reduce New Zealand's stigma and discrimination against people experiencing mental illness (Health Promotion Agency, 2018). Such anti-stigma campaigns have resulted in modest improvements, decreasing stigmatising attitudes and increasing knowledge, which in turn has been associated with an increase in help-seeking behaviour (Carpiniello \& Pinna, 2017).

Interestingly, few participants perceived media stories about suicide to be an important cause of youth suicide, 
with participants wanting more suicide awareness, not less. This is despite the fact that empirical research suggests that media reports of suicide can provoke copycat suicides (Stack, 2005) and suicide contagion (Gould, Jamieson, \& Romer, 2003). Participants in the present study seem to be endorsing the argument that public awareness and education about where to seek help can help to prevent suicides (Gluckman, 2017), much like participants in Heled and Read's (2005) study, who suggested increasing media stories about suicide could be beneficial. New Zealand's guidelines for the responsible reporting of suicides encourage reports about suicide prevention (Ministry of Health, 2011). Perhaps reports with this angle should be more prominent in the media than they are at present, to increase public awareness of suicide and ways to get help.

Notably missing in participants' descriptions of the causes of youth suicide were attributions to genetic and biological causes, with participants instead emphasising situational causes of suicide such as bullying and social pressures. This is consistent with Heled and Read's (2005) findings. In some ways, the participants' sole emphasis on situational factors is at odds with the research literature: There is, for example, strong evidence that suicidal behaviour is partially heritable (Baldessarini \& Hennen, 2004; Brent \& Mann, 2005; Voracek \& Loibl, 2007). Whether this difference between the beliefs of youth and the research evidence is a problem is an open question, although health professionals should certainly be aware that family history of suicide is a risk factor for suicide in young people (see Agerbo, Nordentoft, \& Mortensen, 2002).

\section{References}

Agerbo, E., Nordentoft, M., \& Mortensen, P. B. (2002). Familial, psychiatric, and socioeconomic risk factors for suicide in young people: Nested case-control study. British Medical Journal, 325(7355), 74. doi:https://doi.org/10.1136/bmj.325.7355.74

Baldessarini, R. J., \& Hennen, J. (2004). Genetics of suicide: An overview. Harvard Review of Psychiatry, 12(1), 1-13. doi:https://doi.org/10.1080/10673220490425915

Beautrais, A. L. (2003). Suicide in New Zealand II: A review of risk factors and prevention. New Zealand Medical Journal, 116(1175).

Brent, D. A., \& Mann, J. J. (2005). Family genetic studies, suicide, and suicidal behavior. Paper presented at the American Journal of Medical Genetics Part C: Seminars in Medical Genetics.

Carpiniello, B., \& Pinna, F. (2017). The reciprocal relationship between suicidality and stigma. Frontiers in Psychiatry, 8(35), 1-9. doi:https://doi.org/10.3389/fpsyt.2017.00035

Coronial Services of New Zealand. (2018). Annual suicide statistics since 2011. Retrieved from https://coronialservices.justice.govt.nz/suicide/annualsuicide-statistics-since-2011/

Corrigan, P. W., Angell, B. A., Davidson, L., Marcus, S. C., Salzer, M. S., Kottsieper, P., . . . Stanhope, V. (2012). From adherence to self-determination: Evolution of a treatment paradigm for people with serious mental

\section{Practical Implications/ Recommendations}

Despite the finding that many students would seek help from a professional service for a suicidal friend, they largely perceived such services to be inadequate for several reasons, as previously mentioned. To challenge and change this perception, mental health services should consider taking steps to increase accessibility. Even the perception of barriers to accessibility could be problematic, because if youth believe these services are difficult to access they likely will not try to access them, regardless of whether those barriers actually exist or not.

\section{Limitations}

The main limitations of this study relate to the size and demographic characteristics of the sample. As participation was limited to a convenience sample of students at Massey University, just one of the eight universities in New Zealand, it cannot be assumed the results of this study generalise to other New Zealand university student populations or to the general population of youth worldwide. The small number of males in the sample was problematic, particularly given that males are typically over-represented in suicide statistics in New Zealand (Coronial Services of New Zealand, 2018); and males may hold different views towards suicide and helpseeking compared to females. Such views will not have been accurately encapsulated in the results of this study. Subgroup analyses comparing male and female views could be conducted with the data obtained by the present study. However, no analyses by gender have been presented in this report, other than those pertaining to hypotheses, due to the small number of male participants, and the fact that such analyses were not preregistered. The quantitative data is openly accessible should others wish to explore these possibilities.

illnesses. Psychiatric Services, 63(2), 169-173 doi:https://doi.org/10.1176/appi.ps.201100065

Curtis, C. (2010). Youth perceptions of suicide and helpseeking: 'They'd think I was weak or "mental"'. Journal of Youth Studies, 13(6), 699-715. doi:https://doi.org/10.1080/13676261003801747

Forman, J., \& Damschroder, L. (2007). Qualitative content analysis. In L. Jacoby \& L. A. Siminoff (Eds.), Empirical methods for bioethics: A primer (pp. 39-62): Emerald Group Publishing Limited.

Gluckman, P. (2017). Youth suicide in New Zealand: A discussion paper. Retrieved from http://www.pmcsa.org.nz/wp-content/uploads/17-07-26Youth-suicide-in-New-Zealand-a-Discussion-Paper.pdf

Gould, M., Jamieson, P., \& Romer, D. (2003). Media contagion and suicide among the young. American Behavioral Scientist, 46(9), 1269-1284. doi:https://doi.org/10.1177\%2F0002764202250670

Head, M. L., Holman, L., Lanfear, R., Kahn, A. T., \& Jennions, M. D. (2015). The extent and consequences of p-hacking in science. PLoS Biology, 13(3), e1002106. doi:https://doi.org/10.1371/journal.pbio.1002106

Health Promotion Agency. (2018). Like minds, like mine. Retrieved from https://www.likeminds.org.nz/

Heled, E., \& Read, J. (2005). Young peoples' opinions about the causes of, and solutions to, New Zealand's high youth suicide rate. Suicide and Life-Threatening Behavior. 35(2), 170-180. doi:https://doi.org/10.1521/suli.35.2.170.62881 
Mental Health Commission. (2012). Blueprint II: How things need to be. Retrieved from https://www.hdc.org.nz/media/1075/blueprint-ii-howthings-need-to-be.pdf

Ministry of Health. (2011). Reporting suicide: A resource for the media. Retrieved from https://www.health.govt.nz/system/files/documents/publi cations/reporting-suicide-a-resource-for-mediadec2011.pdf

Ministry of Health. (2017). Indicator: Psychological distress (high or very high probability of anxiety of depressive disorder, K10 score >12). Retrieved from https://minhealthnz.shinyapps.io/nz-health-survey-201617-annual-data-explorer/_w_b7c105f9/\#!/exploreindicators

Ministry of Social Development. (2016). The social report 2016. Wellington, New Zealand. Retrieved from http://socialreport.msd.govt.nz/documents/2016/msd-thesocial-report-2016.pdf

New Zealand Government. (2018). He ara oranga: Report of the Government Inquiry into Mental Health and Addiction. Wellington, New Zealand. Retrieved from https://mentalhealth.inquiry.govt.nz/inquiry-report/heara-orangal

New Zealand Union of Students' Associations. (2018). University counselling statistics. Retrieved from https://d3n8a8pro7vhmx.cloudfront.net/students/pages/29 5/attachments/original/1540925981/_University_Counsell ing_Statistics.pdf?1540925981

Nosek, B. A., Ebersole, C. R., DeHaven, A. C., \& Mellor, D. T. (2018). The preregistration revolution. Proceedings of the National Academy of Sciences, 115(11), 26002606. doi:https://doi.org/10.1073/pnas.1708274114

Open Science Collaboration. (2015). Estimating the reproducibility of psychological science. 349(6251), aac4716. doi:https://doi.org/10.1126/science.aac4716

Pashler, H., \& Wagenmakers, E. J. (2012). Editors' introduction to the special section on replicability in psychological science a crisis of confidence? Perspectives on Psychological Science, 7(6), 528-530. doi:https://doi.org/10.1177\%2F1745691612465253

R Core Team. (2018). R: A language and environment for statistical computing. Vienna, Austria: R Foundation for Statistical Computing. Retrieved from https://www.Rproject.org/

Sheehan, L., Nieweglowski, K., \& Corrigan, P. W. (2017). Structures and types of stigma. In W. Gaebel, W. Rössler, \& N. Sartorius (Eds.), The stigma of mental illness - End of the story? (pp. 43-66). Switzerland: Springer International Publishing.

Simmons, J. P., Nelson, L. D., \& Simonsohn, U. (2011). False-positive psychology: Undisclosed flexibility in data collection and analysis allows presenting anything as significant. Psychological Science, 22(11), 1359-1366. doi:https://doi.org/10.1177\%2F0956797611417632

Stack, S. (2005). Suicide in the media: A quantitative review of studies based on nonfictional stories. Suicide and Life-Threatening Behavior, 35(2), 121-133. doi:https://doi.org/10.1521/suli.35.2.121.62877

Stallman, H. M. (2010). Psychological distress in university students: A comparison with general population data. Australian Psychologist, 45(4), 249-257. doi:https://doi.org/10.1080/00050067.2010.482109

Stubbing, J., \& Gibson, K. (2018). Young people's explanations for youth suicide in New Zealand: A thematic analysis. Journal of Youth Studies, 1-13. doi:https://doi.org/10.1080/13676261.2018.1516862
Voracek, M., \& Loibl, L. M. (2007). Genetics of suicide: A systematic review of twin studies. Wiener klinische Wochenschrift, 119(15), 463-475. doi:https://doi.org/10.1007/s00508-007-0823-2

World Health Organization. (2018). Suicide. Retrieved from https://www.who.int/news-room/fact-sheets/detail/suicide

\section{Corresponding Author}

Mikayla Holman

School of Psychology, Massey University

Private Bag 102-904,

North Shore, Auckland 0745

Email: mikaylaholman@hotmail.com 